were tested on significance by generalized estimation equations (GEE) (2). This method modeled changes of health by multivariate logistic regression adjusting for sex, education, number of comorbidities and the baseline score over both follow-ups for each scale.

Results: Italian-speaking patients $(n=61)$ showed higher proportions of males, lower educated and less burdened by comorbidities than German-speaking patients $(n=63)$. At baseline, physical and psychosocial health, depression and anxiety of the Italian-speaking patients were worse than German-speaking patients, with the exception of less pain in the Italian-speaking patients on the SF-36. Changes of health showed more improvement in German- than in Italian-speaking patients on all scales and at both follow-ups. In GEE, the highest differences were observed in SF-36 physical functioning ( $p=0.035)$, HADS anxiety $(p=0.038)$ and HADS depression $(p=0.023)$. On SF-36 bodily pain, the difference was not significant $(\mathrm{p}=0.166)$.

Conclusions: This study detected that short- and midterm outcome of Italianspeaking patients was worse than that of German-speaking patients, even after adjustment for baseline differences. The reasons for this study's results remain unclear, but may have consequences for future management of Italian-speaking patients in interdisciplinary pain management programs. Considering language as a proxy for acculturation, this supports the hypothesis that patients with lower level of acculturation may have special needs in therapeutic management. A cultural sensitive approach in a multidisciplinary pain program might enhance the positive outcome in the short- and mid-term (3).

[1] Green CR, Anderson KO, Baker TA, Campbell LC, Decker S, Fillingim RB, Kalauokalani DA, Lasch KE, Myers C, Tait RC, Todd KH, Vallerand AH. The unequal burden of pain: confronting racial and ethnic disparities in pain. Pain Med 2003;4:277-94.

[2] Twisk JW. Generalized estimating equations. Applied longitudinal data analysis for epidemiology. 2nd ed. Cambridge: Cambridge University Press; 2013: p 57-68.

[3] Benz T, Lehmann S, Brioschi R, Elfering A, Aeschlimann A, Angst F. Comparison of short- and mid-term outcome of Italian- and German-speaking patients after an interdisciplinary pain management program. Disabil Rehabil 2017; in preparation.

Disclosure of Interest: None declared

DOI: 10.1136/annrheumdis-2017-eular.5888

\section{THU0719 LONG-TERM COURSE OF HEALTH AND WORKING CAPACITY AFTER A REHABILITATION PROGRAM FOR WHIPLASH INJURY}

T. Benz ${ }^{1}$, P. Haiduk ${ }^{1}$, S. Lehmann ${ }^{1}$, F. Gysi-Klaus ${ }^{1}$, B.A. Michel ${ }^{2}$

A. Aeschlimann ${ }^{1}$, F. Angst ${ }^{1} .{ }^{1}$ Research Department, RehaClinic, Bad Zurzach;

${ }^{2}$ Clinic of Rheumatology, University Hospital of Zurich, Zurich, Switzerland

Background: Persistent pain and disability of whiplash injury associated disorders (WAD) cause high burden for the individual and costs for healthcare.
Objectives: The aim of this study was to determine state and change of health and working-capacity five years after a standardized inpatient pain management program of four weeks.

Methods: This prospective cohort study quantified health and quality of life by the generic Short Form 36 (SF-36, 100=best), the neck-specific Northern American Spine Society (NASS) form, and the Coping Strategies Questionnaire (CSQ). SF-36 data were compared to age-, sex-, and comorbidity-specific German population norms (1). Changes of health were determined using effect sizes (ES) at the 6 month and the 60 month follow-up. Changes of health were determined using effect sizes (ES) (2).

Results: The 59 participants had mean age of 40.3 years ( $s d=12.3$ ), $83 \%$ were women, and $37 \%$ had one or more comorbidites. At 5 years, health was worse on all SF-36 scales when compared to the norms $(p<0.001)$, varying from mean 41.5 , norm 82.3 on role physical to mean 65.7 , norm 71.0 on mental health (all $\mathrm{p}<0.001)$

Table 1

Effect sizes (ES) Entry to 60 months 6 months to 60 months

SF-36 Physical functioning

\begin{tabular}{ll}
0.99 & 0.16 \\
2.22 & 0.83 \\
1.61 & 0.78 \\
0.89 & 0.32 \\
0.71 & 0.47 \\
0.61 & 0.30 \\
1.12 & 0.56 \\
0.78 & 0.26 \\
1.03 & 0.62 \\
\hline
\end{tabular}

SF-36 Role physical

SF-36 Bodily pain

SF-36 Vitality

SF-36 Social functioning

SF-36 Mental health

NASS Pain

NASS Function

CSQ Catastrophizing

Median working capacity improved from 0 at entry to 21 at 6 months and to 30 hours/week at 5 years.

Conclusions: Moderate to large long-term effects were observed. Substantial improvements still occurred between 6 and 60 months after start of the pain program, especially in pain, catastrophizing, and physical role performance. Improvements observed after the inpatient pain program can be maintained and expanded in the long-term at home (3).

References:

[1] Kurth BM, Ellert U. The SF-36 questionnaire and its usefulness in population studies: Results of the German Health Interview and Examination Survey 1998. Soz Praeventivmed 2002:47:266-277.

[2] Kazis ES, Anderson JJ, Meenan RF. Effect sizes for interpreting changes in health status. Med Care 1989;27(3 Suppl):S178-89.

[3] Haiduk P, Benz T, Lehmann S, Gysi-Klaus F, Aeschlimann A, Michel BA, Angst F. Interdisciplinary rehabilitation after whiplash injury: An observational prospective five year outcome study. Medicine 2017; in press.

Disclosure of Interest: None declared

DOI: 10.1136/annrheumdis-2017-eular.6178 